\title{
Responses of South and East Asian summer monsoons to different land-sea temperature increases under a warming scenario
}

\author{
SUN Ying ${ }^{*} \&$ DING YiHui \\ National Climate Center, Beijing 100081, China
}

Received March 7, 2011; accepted May 23, 2011

\begin{abstract}
We used outputs from climate models that participated in the fourth assessment (AR4) of the Intergovernmental Panel on Climate Change (IPCC) to evaluate the responses of the South Asian summer monsoon (SASM) and the East Asian summer monsoon (EASM) circulations to different warming over land and ocean under a medium warming scenario, SRES A1B. Our results suggest that, even though near-surface warming over the Tibetan Plateau (TP) is greater than that over the tropical Indian Ocean (TIO) and the northwestern Pacific (NWP), the upper-tropospheric land-sea thermal contrasts between the TP and the TIO (TP-TIO) and between the TP and the NWP (TP-NWP) will decrease. At interdecadal and longer time scales, the change in the SASM circulation is consistent with the TP-TIO upper-troposphere thermal contrast. Conversely, the change in the EASM circulation is consistent with the TP-NWP lower-troposphere thermal contrast. However, at the interannual time scale, both changes in the EASM and SASM are significantly correlated with the upper-troposphere thermal contrast. Further analyses suggest that increases in moisture and changes in cloud cover induced by global warming may cause amplified upper-tropospheric warming over the TP and the oceans resulting in inconsistent changes in the vertical temperature distribution over these regions. Because the warming over the TIO and NWP is greater than that over the TP, the TP-TIO meridional and TP-NWP zonal thermal contrasts will both decrease. However, at the lower layer, the difference in thermal capacity between land and sea result in a larger thermal effect in the near-surface region of the TP than those over the surrounding oceans. We showed that a range of factors that affect thermal conditions will likely cause changes in the Asian monsoon across a range of time scales under a warming scenario. These changes reflect differences in the influence of the greenhouse effect and natural variability.
\end{abstract}

South and East Asian summer monsoons, thermal contrasts, global warming

Citation: Sun Y, Ding Y H. Responses of South and East Asian summer monsoons to different land-sea temperature increases under a warming scenario. Chinese Sci Bull, 2011, 56: 2718-2726, doi: 10.1007/s11434-011-4602-0

Against the background of global climate change, changes in temperature can differ significantly over land and ocean due to differences in their thermal capacities. In the Asian monsoon region, the near-surface temperature rises more quickly on the Eurasian continent than that in the surrounding oceans, increasing the near-surface land-sea thermal contrast. Therefore, it can be theoretically deduced that the Asian summer monsoon circulation may strengthen as a result of global climate change. However, most climate models have shown that the South Asian summer monsoon (SASM) circulation may actually weaken, whereas the East

*Corresponding author (email: sunying@cma.gov.cn)
Asian summer monsoon (EASM) circulation may strengthen [1-3]. A recent study [4] suggested that the relationship between the SASM circulation and land-sea thermal differences may change in the future. SASM circulation is projected to weaken because of a decrease in the land-sea thermal contrast in the upper-troposphere, which is in contrast to the increase in thermal differences in the near-surface layer. However, the reason for changes in the EASM circulation remains unclear.

The variation in thermal differences between the Eurasian continent and its surrounding oceans are an important driving force for the formation of the Asian summer monsoon. Given this, a number of researchers have studied their 
influence. For example, land-sea differences in near-surface temperature [5,6], 200-500 hPa thickness [7,8], 200-500 hPa temperature [9], 200-1000 hPa thickness [10], and $500 \mathrm{hPa}$ geopotential height [11] have been used to analyze the relationship between the Asian summer monsoon and changes in the land-sea thermal contrast. These studies have concluded that the changes in the Asian monsoon are closely related to the changes in land-sea thermal contrasts at a range of time scales (seasonal, decadal, interdecadal). The strengthening (weakening) of the thermal contrasts between the Eurasian continent and the surrounding oceans generally corresponds to enhancement (weakening) of the Asian summer monsoon. In East Asia, such changes are related to zonal thermal differences between the Asian continent and the northwestern Pacific. Conversely, in South Asia, the changes are associated with meridional thermal differences between the Asian continent and the Indian Ocean. The thermal conditions in the Tibetan Plateau (TP) are deemed to have an important role therein.

Despite these previous studies, it is clear that several issues related to changes in the EASM have received little attention. These include the influence of differences in landsea temperature increases and whether this influence differs from that in South Asia. An understanding of these processes will aid projections of changes in the monsoon circulation and the mechanisms driving such changes. To address this, we conducted a detailed analysis of changes in the EASM based on a study by Sun et al. [4] (hereafter referred to as SunGRL). We evaluated the influence of physical factors on changes in the EASM and SASM based on changes in the land-sea thermal contrast for a range of time scales.

\section{Data and methods}

We used outputs from the climate models that participated in the fourth assessment report (AR4) of the Intergovernmental Panel on Climate Change (IPCC) under a medium emission scenario, SRESA1B. Eight standards were established for model selection to determine whether the models were adequate for simulating variables in the SASM, EASM, and TP regions (Table 1). These standards include a reasonable simulation of the correlation coefficients between monsoon indices and thermal differences in the upperand lower-layers, and yield a desirable reproduction of the EASM and SASM circulation fields. Based on the outputs

Table 1 Correlation coefficients among monsoon indices, $\mathrm{TC}_{\mathrm{upper}}, \mathrm{TC}_{\mathrm{lower}}$, for models in East Asia (a) and South Asia (b)

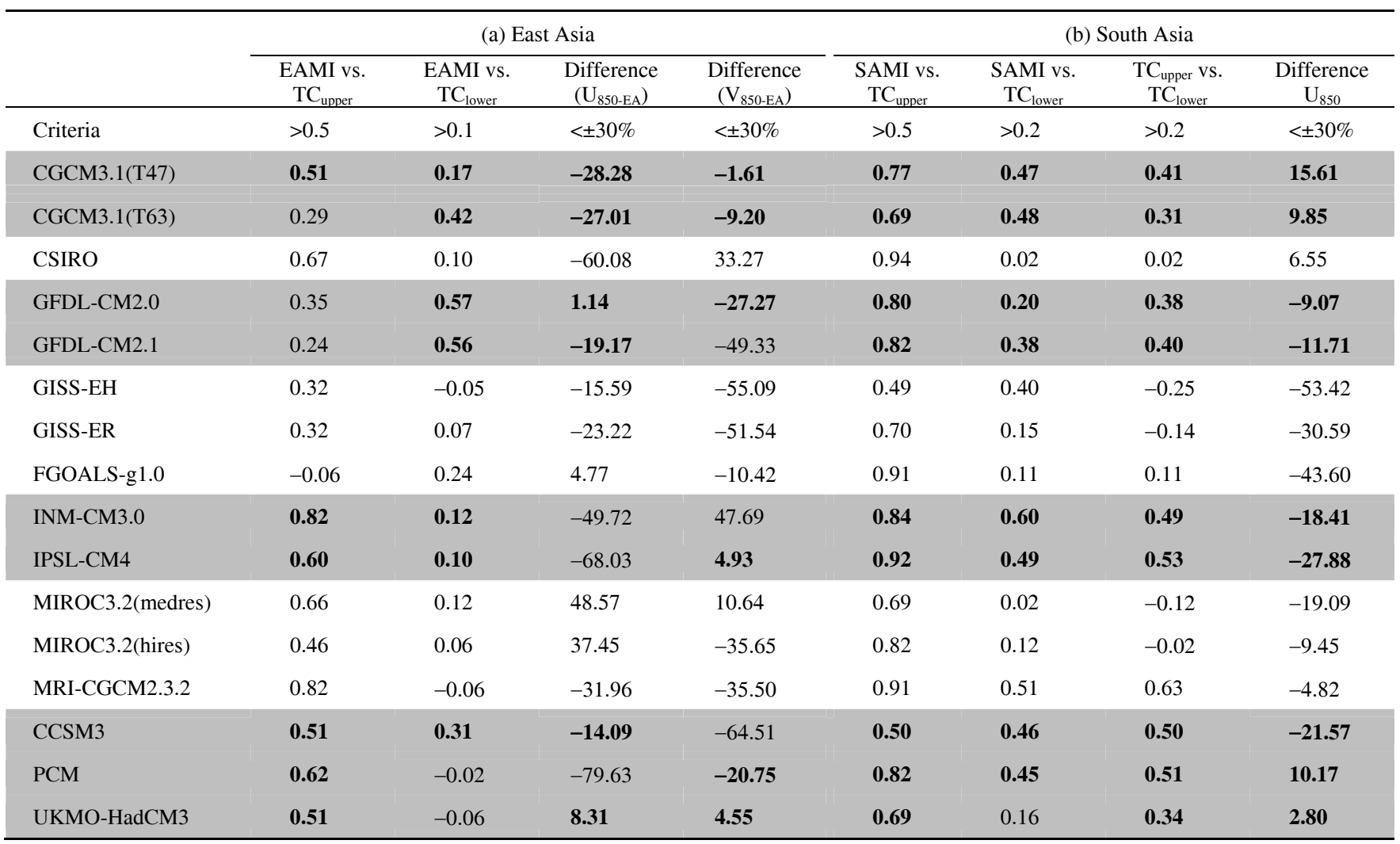

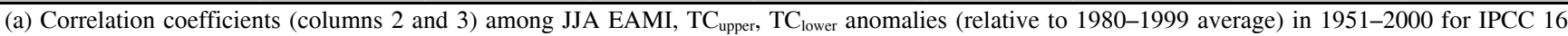

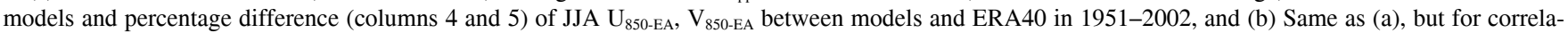
tions (columns 6, 7 and 8) among June-July-August-September (JJAS) SAMI, $\mathrm{TC}_{\text {upper }}, \mathrm{TC}_{\text {lower }}$ anomalies and percentage difference (column 9) of JJAS U ${ }_{850}$ averaged in the region $\left(0^{\circ}-20^{\circ} \mathrm{N}, 40^{\circ}-100^{\circ} \mathrm{E}\right)$ between models and ERA40. Line 3 shows the criteria for model selection. The values passing the selection criteria are marked in bold black. The models meeting 6 or more selection criteria are shaded by grey areas. 
from the 16 available models, we selected nine models that meet at least six standards. These include: CGCM3.1(T47), CGCM3.1(T63), GFDL-CM2.0, GFDL-CM2.1, INM-CM3.0, IPSL-CM4, CCSM3, PCM, and UKMO-HadCM3. When comparing results with the SunGRL study, the different model ensembles may explain both minor and major differences. Therefore, it is important to develop a set of reasonable metrics for model selection to allow comparison of climate projections between different studies and different regions. The use of uniform metrics is an important issue for future climate change research.

The monthly data from the nine climate models for $20 \mathrm{C} 3 \mathrm{M}$ and SRESA1B were interpolated onto grid points of $2.5^{\circ} \times 2.5^{\circ}$ then converted to an arithmetic average. Detailed information on the models is available at http://www-pcmdi. llnl.gov/ipcc/about_ipcc.php or in Meehl et al. [12]. In addition, NCEP and ERA40 reanalysis data were used to evaluate the ability of the models to simulate the current climate. This paper is primarily focused on the results from the 9model ensemble. Therefore, issues surrounding model uncertainty will not be discussed.

We used the SASM index defined by Webster and Yang [13] and also applied in the SunGRL paper. The index describes the differences between $850 \mathrm{hPa}\left(\mathrm{U}_{850}\right)$ and $200 \mathrm{hPa}$ $\left(\mathrm{U}_{200}\right)$ zonal winds averaged in the region $0^{\circ}-20^{\circ} \mathrm{N}$, $40^{\circ}-100^{\circ} \mathrm{E}$ and is expressed as $\mathrm{SAMI}=\mathrm{U}_{850}-\mathrm{U}_{200}\left(0^{\circ}-20^{\circ} \mathrm{N}\right.$, $\left.40^{\circ}-100^{\circ} \mathrm{E}\right)$. This index reasonably describes the thermal driving properties of the SASM and thus, indicates the importance of horizontal thermal differences in monsoon evolution. In the EASM region, there is a clear relationship between the meridional wind and the land-sea thermal contrasts. Therefore, we used the $850 \mathrm{hPa}$ meridional wind $\left(\mathrm{V}_{850 \text {-EA }}\right)$, averaged in the region $\left(10^{\circ}-35^{\circ} \mathrm{N}, 110^{\circ}-125^{\circ} \mathrm{N}\right)$, as an index of the EASM: EAMI $=\mathrm{V}_{850 \text {-EA }}\left(10^{\circ}-35^{\circ} \mathrm{N}, 110^{\circ}-\right.$ $125^{\circ} \mathrm{N}$ ). Wang et al. [14] pointed out that some EASM indices defined by different authors based on $850 \mathrm{hPa}$ winds can indicate the changes in the EASM in a conventional sense. In addition, other indices are discussed in this paper, including changes in the $850 \mathrm{hPa}$ zonal winds (hereafter $\left.\mathrm{U}_{850 \text {-EA }}\right)$ averaged in the $\mathrm{V}_{850 \text {-EA }}$ region $\left(10^{\circ}-35^{\circ} \mathrm{N}, 110^{\circ}-\right.$ $125^{\circ} \mathrm{N}$ ) and the difference in SLP (hereafter DSLP) between the TP and the northwestern Pacific (NWP) (i.e. DSLP= SLP(TP)-SLP(NWP)).

We calculated the changes in land-sea thermal contrasts in the upper- and lower-troposphere, respectively. We selected the TP, the tropical Indian Ocean (TIO), and the NWP to represent three important areas (Figure 1). The uppertropospheric thermal contrasts were calculated using a 200 $500 \mathrm{hPa}$ thickness, while the lower-tropospheric thermal contrasts were calculated using the near-surface $(2 \mathrm{~m})$ temperature over the TP and 500-850 hPa temperatures over the TIO and NWP. Thus, the upper- and lower-tropospheric thermal contrasts (hereafter $\mathrm{TC}_{\text {upper }}$ and $\mathrm{TC}_{\text {lower }}$ ) over these three areas can be expressed as

$\mathrm{TC}_{\text {upper }}(\mathrm{TP}-\mathrm{TIO})=$ Thickness $(200-500 \mathrm{hPa}, \mathrm{TP})-$ Thick- ness (200-500 hPa, TIO)

$\mathrm{TC}_{\text {lower }}(\mathrm{TP}-\mathrm{TIO})=$ Temperature (near-surface $\left.[2 \mathrm{~m}], \mathrm{TP}\right)-$ Temperature (500-850 hPa, TIO)

$\mathrm{TC}_{\text {upper }}(\mathrm{TP}-\mathrm{NWP})=$ Thickness $(200-500 \mathrm{hPa}, \mathrm{TP})-$ Thickness (200-500 hPa, NWP)

$\mathrm{TC}_{\text {lower }}(\mathrm{TP}-\mathrm{NWP})=$ Temperature $($ near-surface $[2 \mathrm{~m}], \mathrm{TP})-$ Temperature (500-850 hPa, NWP)

in which $\mathrm{TC}_{\text {upper }}$ (TP-TIO) and $\mathrm{TC}_{\text {lower }}$ (TP-TIO) are related to the changes in the SASM whereas $\mathrm{TC}_{\text {upper }}$ (TP-NWP) and $\mathrm{TC}_{\text {lower }}$ (TP-NWP) are linked to changes in the EASM. For convenience, $\mathrm{TC}_{\text {upper }}$ and $\mathrm{TC}_{\text {lower }}$ are used hereafter to represent the upper- and lower-tropospheric thermal differences over the TP-TIO and TP-NWP regions, respectively. Because this study is primarily focused on the relationship between the thermal contrasts and changes in monsoon circulation (unless otherwise stated, the Asian summer monsoon refers to the monsoon circulation) changes in monsoon precipitation is not discussed.

\section{Changes in the Asian summer monsoon circulation and land-sea thermal differences under SRESA1B}

Figure 1 illustrates the 9-model mean $850 \mathrm{hPa}$ winds and sea-level pressure (SLP) for the period 1980-1999. The models are generally able to reproduce the distribution of SLP and wind fields in Asia. Because the land is heated to a greater degree in the summer, it becomes significantly warmer than the oceans. The Eurasian continent is controlled by thermal low pressure whereas the oceans are controlled by high pressure systems. The thermal contrasts due to differences in the warming of the land and oceans drives the monsoon circulation, forming strong southwesterly winds flowing from the Indian Ocean to the Bay of Bengal, all the way to the northern South China Sea and then turning into East Asia and the western Pacific. The southwesterly winds affect the climate in East Asia with the southerly winds originating from the northwestern flank of the NWP anticyclone. These patterns illustrate that the models capture the major features of the Asian summer monsoon system and have the ability to simulate monsoon circulation and air pressure fields. In addition, we verified the models performance in simulating the relationship between monsoon circulation and the land-sea thermal contrasts. When compared with reanalysis of ERA40 and NCEP (Figure 1, comparison with NCEP data not shown), the 9-model ensemble underestimates the magnitude of the SAMI, EAMI, $\mathrm{TC}_{\mathrm{upper}}$, and $\mathrm{TC}_{\text {lower }}$. However, the models do reproduce the negative trends of these indices in the past 50 years. The 9-model mean linear trends (1951-2000) for EAMI and SAMI are $-0.026 \mathrm{~m} \mathrm{~s}^{-1} /$ decabe and $-0.122 \mathrm{~m} \mathrm{~s}^{-1} /$ decabe, respectively. Furthermore, five of the nine models reproduced the weakening trend in the EASM (data not shown). This demon- 
strates that, compared with earlier climate models, the current generation of climate models has improved simulation of the EASM. The models are also able to generally simulate the correlations among SAMI, EAMI, $\mathrm{TC}_{\text {upper, }}$ and $\mathrm{TC}_{\text {lower. }}$ The correlation coefficients $(r)$ are 0.33 (ERA40, 1958-2002), 0.40 (NCEP, 1951-2000), and 0.51 (models, 1951-2000) between EAMI and $\mathrm{TC}_{\text {upper }}$ and 0.45 (NCEP), 0.29 (ERA40), and 0.25 (models) between EAMI and $\mathrm{TC}_{\text {lower }}$. The correlations between SAMI and $\mathrm{TC}_{\text {upper }}$ are 0.75 (NCEP), 0.73 (ERA40), and 0.71 (models). The correlations between SAMI and $\mathrm{TC}_{\text {lower }}$ were 0.49 (NCEP), 0.41 (ERA40), and 0.38 (models). Thus, the models generally captured the dynamic relationship between monsoon circulation and the land-sea thermal contrast, and can be used to analyze the future changes in monsoon circulation and the relevant variables.

Figure 2 illustrates the June-July-August (JJA) mean changes (relative to 1980-1999 average) in SAMI, EAMI, $\mathrm{TC}_{\text {upper, }}$, and $\mathrm{TC}_{\text {lower }}$ over TP-TIO-NWP between 2000 and 2099 under SRESA1B. In South Asia, the results are consistent with the 7-model ensemble used in the SunGRL paper. The changes in SAMI and $\mathrm{TC}_{\text {upper }}$ are similar, in terms of the same long-term weakening trend and being closely correlated at interannual $(r=0.73)$ and interdecadal $(r=0.96)$

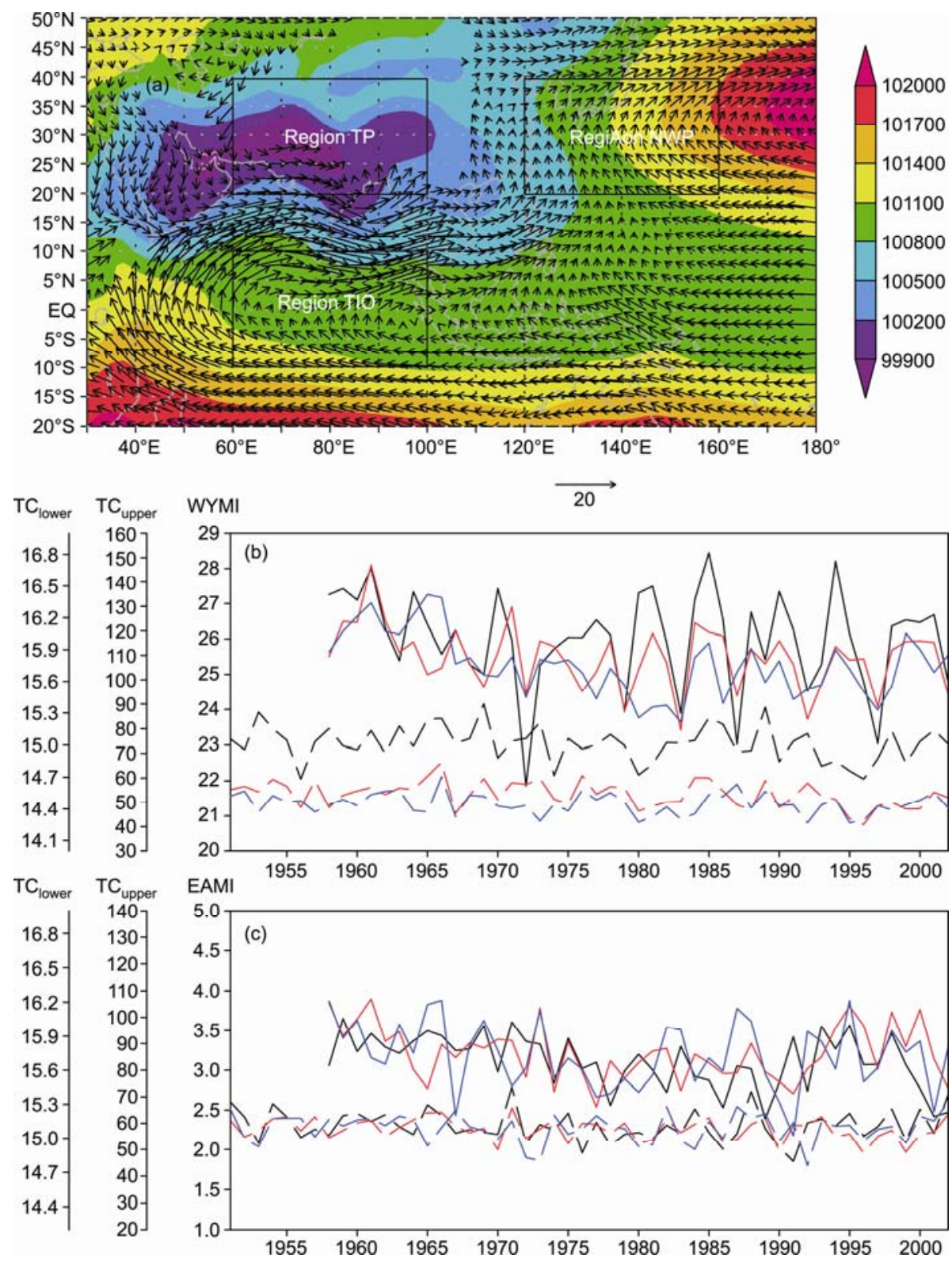

Figure 1 (a) IPCC 9-model mean June-July-August (JJA) sea level pressure (Pa, shaded area) and $850 \mathrm{hPa}$ winds (m/s, arrows) for 1980-1999 (blank areas in wind fields represents geographical heights greater than $1500 \mathrm{~m})$. (b) Monsoon index SAMI (m/s, black line), $\mathrm{TC}_{\text {upper }}\left(\mathrm{gpm}, \mathrm{red}\right.$ line) and $\mathrm{TC}_{\text {lower }}(\mathrm{K}$, blue

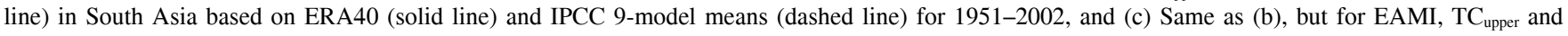
$\mathrm{TC}_{\text {lower }}$ in East Asia. 


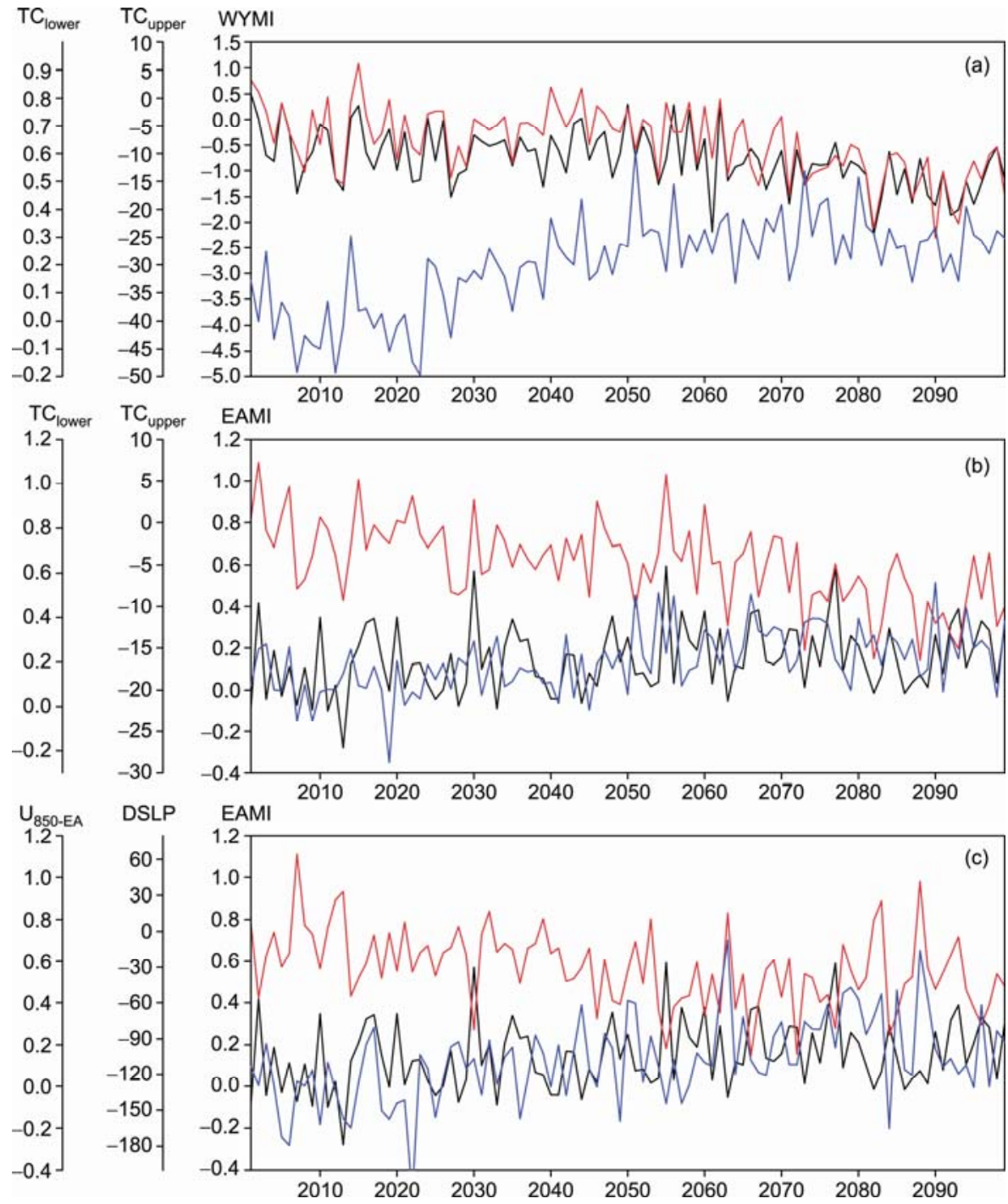

Figure 2 IPCC 9-model mean (a) JJA changes (relative to 1980-1999 average) in SAMI (m/s, black line), $\mathrm{TC}_{\text {upper }}$ (gpm, red line) and TC lower $(\mathrm{K}$, blue line) for 2000-2099 in South Asia. (b) Same as in (a), but for EAMI (m/s, black line), $\mathrm{TC}_{\text {upper }}$ and $\mathrm{TC}_{\text {lower }}$ in East Asia. (c) JJA changes in EAMI (m/s, black line), $\mathrm{U}_{850-\mathrm{EA}}(\mathrm{m} / \mathrm{s}$, blue line) and DSLP (Pa, red line). Figure 2(a) was redrawn with IPCC 9 models based on Figure 2(a) in the SunGRL paper.

time scales. In contrast, changes in SAMI are opposite those in $\mathrm{TC}_{\text {lower }}$ in the lower-troposphere $(r=0.35$ and -0.48 at interannual and interdecadal time scales, respectively). This indicates that the influence of thermal differences on the SASM circulation is more significant in the upper-troposphere than that in the lower-troposphere.

In East Asia, the changes in $\mathrm{TC}_{\text {upper }}$ and $\mathrm{TC}_{\text {lower }}$ follow an increasing and decreasing trend, respectively, which is similar to the trends in South Asia. However, the EAMI will increase, which is consistent with $\mathrm{TC}_{\text {lower }}$ but opposite that in $\mathrm{TC}_{\text {upper }}$. The correlation coefficients at the interannual and interdecadal time scales are 0.01 and 0.74 , respectively, between EAMI and $\mathrm{TC}_{\text {lower }}$ and 0.32 and -0.45 , respectively, between EAMI and $\mathrm{TC}_{\text {upper. }}$ Thus, the change in the EASM is primarily influenced by $\mathrm{TC}_{\text {lower }}$ at interdecadal and longer time scales, but is closely correlated with $\mathrm{TC}_{\text {upper }}$ at the interannual time scale. This suggests that the long-term changes in the EASM result primarily from the strengthening of $\mathrm{TC}_{\text {lower. }}$.

To further investigate the changes in the EASM, we evaluated the temporal evolution of changes in DSLP, EAMI, and $\mathrm{U}_{850-\mathrm{EA}}$ (relative to the 1981-2000 average) (Figure 2(c)). There will be a negative trend in the DSLP over the TP-NWP area between 2001 and 2099, indicating an increased sea-land pressure gradient force along the East Asian coast (Note: The sea-land air pressure gradient force is oriented toward the land from the ocean, thus the negative trend implies a strengthened pressure gradient), and thus a weakening EASM. This may be caused by weakening of the SLP on the Eurasian continent because of rapid increases in near-surface temperature. At the interdecadal time scale, the DSLP is correlated more closely with $\mathrm{TC}_{\text {lower }}(r=-0.86)$ than with $\mathrm{TC}_{\text {upper }}(r=0.46)$, while at the interannual time scale, the correlation with $\mathrm{TC}_{\text {upper }}(r=-0.71)$ is more signif- 
icant than with $\mathrm{TC}_{\text {lower }}(r=-0.28)$. These are consistent with those between EAMI and $\mathrm{TC}_{\text {upper }}$ and $\mathrm{TC}_{\text {lower, }}$ i.e. the influence of lower-layer land-sea thermal differences is most evident at longer time scales whereas the influence of the upper-layer thermal differences is evident at the interannual time scale. The correlation coefficients between DSLP and EAMI $\left(\mathrm{V}_{850-\mathrm{EA}}\right)$ reveal a remarkable correlation at both interannual $(r=-0.59)$ and interdecadal $(r=-0.81)$ time scales. Similarly, the correlation between DSLP and $\mathrm{U}_{850 \text {-EA }}$ is also significant ( $r=0.66$ and 0.76 at interannual and interdecadal time scales, respectively). Therefore, the strengthening (weakening) of the sea-land pressure gradient force corresponds to strengthening (weakening) of both meridional and zonal components of the monsoonal winds. This suggests that the difference in the sea-land SLP gradient between NWP and TP is a good indicator of future changes in the EASM, which is consistent with past studies of the relationship between the EASM and the SLP gradient.

Our analyses suggest that the changes in the EASM are more complex than those in the SASM. The changes in SASM are primarily affected by $\mathrm{TC}_{\mathrm{upper}}$ at a full range of time scales. In contrast, the EASM is correlated with $\mathrm{TC}_{\text {lower }}$ at interdecadal and longer time scales and with $\mathrm{TC}_{\text {upper }}$ at the interannual time scale.

\section{Temperature changes in the TP-TIO-NWP under SRESA1B}

We evaluated the factors influencing the changes in monsoon circulation and land-sea thermal contrasts. The timeheight cross-sections of temperature changes over the TP, TIO, and NWP and their linear trends between 2001 and 2099 are illustrated in Figure 3. Under SRESA1B, the vertical distribution of temperature change in these three areas is quite similar during this period. The warming in the upperlayer is clearly more rapid than that in the lower-layer, with a maximum centered around $150-300 \mathrm{hPa}$ and a minimum around the lower-layer. The most intense warming occurred over the TIO (Figure 3(d), red line), with a linear trend of $0.54 \mathrm{~K} /$ decade at $200 \mathrm{hPa}$. The temperature increase over the TP (black line) is relatively small $(0.50 \mathrm{~K} /$ decade at $150 \mathrm{hPa}$ and $200 \mathrm{hPa}$ ). However, in the lower-layer, the near-surface warming trend $(0.34 \mathrm{~K} /$ decade, orange solid line) over the TP is greater than that over the TIO and NWP at the same height. Thus, lower-tropospheric warming over the TP is more rapid than those in the TIO and NWP, while upper-tropospheric warming is slower than those over the TIO and NWP. The increasing trend of higher-layer thickness over the TP, TIO, and NWP is $11.82 \mathrm{gpm} /$ decade, $13.00 \mathrm{gpm} /$ decade, and $12.81 \mathrm{gpm} /$ decade, respectively. Similarly, the trends in lower-layer temperature changes over these three regions are $0.34 \mathrm{~K} /$ decade, $0.31 \mathrm{~K} /$ decade, and $0.32 \mathrm{~K} /$ decade, respectively. These inconsistencies in temperature evolution with height likely explain differences in the change in $\mathrm{TC}_{\text {upper }}$ and $\mathrm{TC}_{\text {lower }}$ in the Asian monsoon region. This also suggests that the links between monsoon circulation and tropospheric land-sea thermal differences will change across a range of time scales in the future.

The latitude-height cross-sections of temperature changes (2080-2099 average minus 1980-1999 average) along the longitude $\left(60^{\circ}-100^{\circ} \mathrm{E}\right)$ and latitude $\left(20^{\circ}-40^{\circ} \mathrm{N}\right)$ belts over the TP are illustrated in Figure 4. The vertical distribution of temperatures changes over the TP, TIO, and NWP are quite similar. However, our data suggest that the greatest warming is centered over the equator along the cross-section of $60^{\circ}-100^{\circ} \mathrm{E}$ (i.e. above the TIO). Along the cross-section of $20^{\circ}-40^{\circ} \mathrm{N}$, the warming center is near $300 \mathrm{hPa}$ over the Pacific and the Atlantic oceans. Thus, in the lower-layer, the near-surface temperature rise on the TP is faster than those in other areas at the same height. This leads to the strengthening of land-sea thermal differences. However, in the upper-layer, the warming centers are all above the surrounding oceans, hence the thermal differences among TP, TIO and NWP will likely weaken.

The changes in meridional thermal differences between the latitude belts over the TP and TIO (i.e. changes in the difference between the $20^{\circ}-40^{\circ} \mathrm{N}$ average and the $10^{\circ} \mathrm{S}-$ $10^{\circ} \mathrm{N}$ average) are illustrated in Figure 5. The meridional thermal differences between these two belts will likely weaken in the future, reflecting the decreased meridional thermal contrasts between the boreal tropics and subtropics in the upper-layer. The maximum of the weakening thermal contrasts is centered above the TP-TIO, almost covering the whole mid- and upper-troposphere (500-150 hPa). The changes in the zonal thermal differences between the longitude belts over the TP and TWP (changes in the difference between the $60^{\circ}-100^{\circ} \mathrm{E}$ average and the $120^{\circ}-160^{\circ} \mathrm{E}$ average) suggest that the upper-layer thermal differences in these two longitude belts will also weaken, with a maximum located over TP-NWP. In contrast to TP-TIO, the lowerlayer thermal gradient over TP-NWP increases across a wider range, with a positive change centered over the TP. This suggests that the increase in the lower-tropospheric thermal differences in this area have a greater influence on the EASM. Thus, our data suggest that, associated global climate change, inconsistencies in the vertical temperature changes lead to thermal gradient changes along the longitude and latitude belts over the TP. This process may be the primary driver of future changes in the Asian monsoon.

Interestingly, the greatest warming centers in the upper layer are all located over surrounding oceans, even though the near-surface rise in temperature is highest in the TP. As pointed out in the SunGRL paper, a rapid increase in the global moisture content at a rate of $\sim 7 \% / \mathrm{K}$ (around $9 \% / \mathrm{K}$ [15] as estimated in the models), will cause the release of latent heat and an increase in high cloud cover because of strengthening convection. In turn, this results in the regions of greatest warming being centered in the upper layer of the tropical oceans $[16,17]$. In the TP, the enhanced upper- 

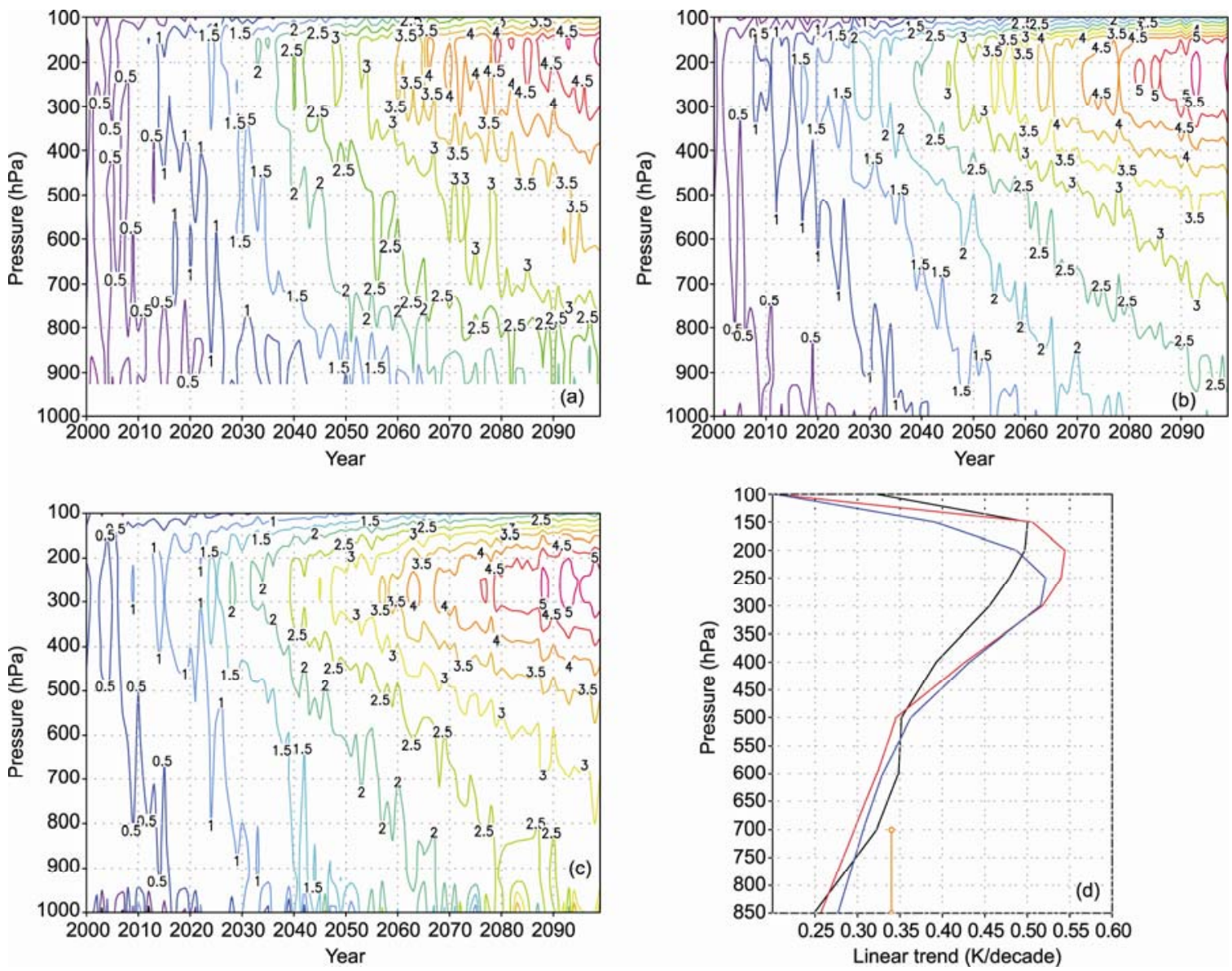

Figure 3 Time-height cross-section of JJA temperature changes (K, relative to 1980-1999 average) based on the IPCC 9-model mean over (a) TP, (b) TIO, and (c) NWP. (d) Trends (K/decade) for 2000-2099 temperatures averaged over TP (black), TIO (red), and NWP (blue) from $850 \mathrm{hPa}$ to $100 \mathrm{hPa}$. The orange line indicates the trend (K/decade) in near-surface temperature over the TP. Figure 3(b) was redrawn with IPCC 9 models based on Figure 3(a) in the SunGRL paper.
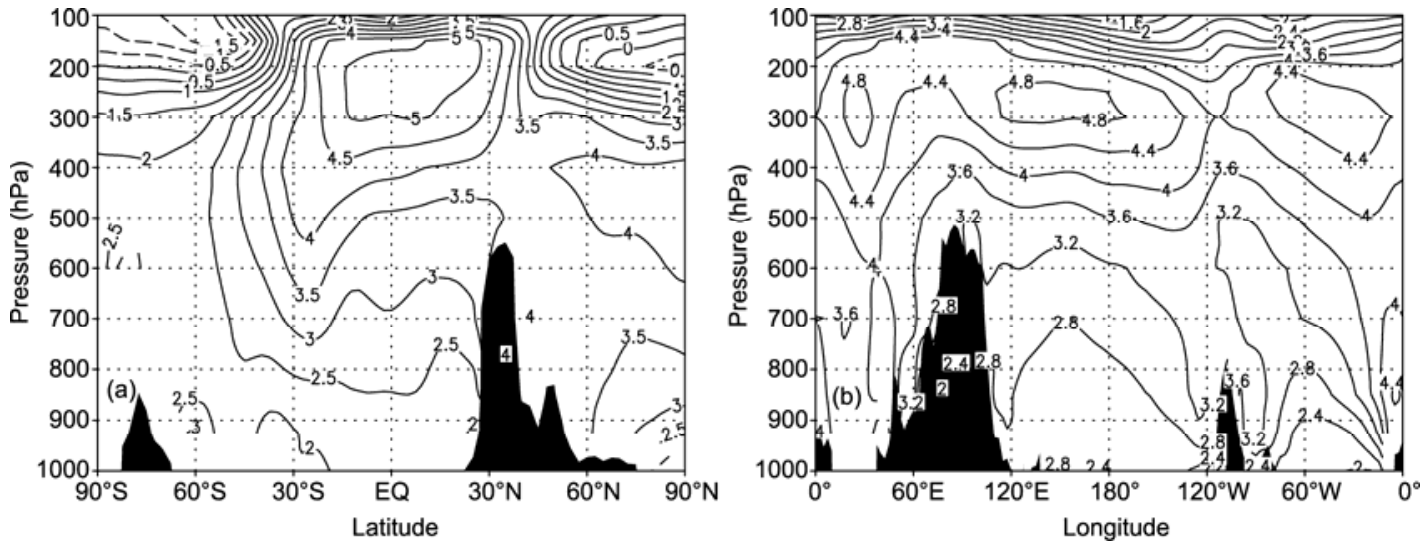

Figure 4 IPCC 9-model mean latitude-height cross-section of JJA temperature changes (K, relative to 1980-1999 average) along the longitude belt (i.e. $60^{\circ}-100^{\circ} \mathrm{E}$ average) over the TP and TIO for 2080-2099. (b) Same as (a), but for the longitude-height cross-section along the latitude belt (i.e., $20^{\circ}-40^{\circ} \mathrm{N}$ average) over the TP and NWP. Figure 4(a) was redrawn with IPCC 9 models based on Figure 3(b) in the SunGRL paper.

tropospheric warming may be related to warm advection from the tropics and the strengthening of long-wave radiation due to an increase in moisture and clouds [18]. Howev- er, such warming is clearly slower than that over the tropical oceans. Our data suggest that enhanced upper-tropospheric warming also occurs over the NWP, with a magnitude 

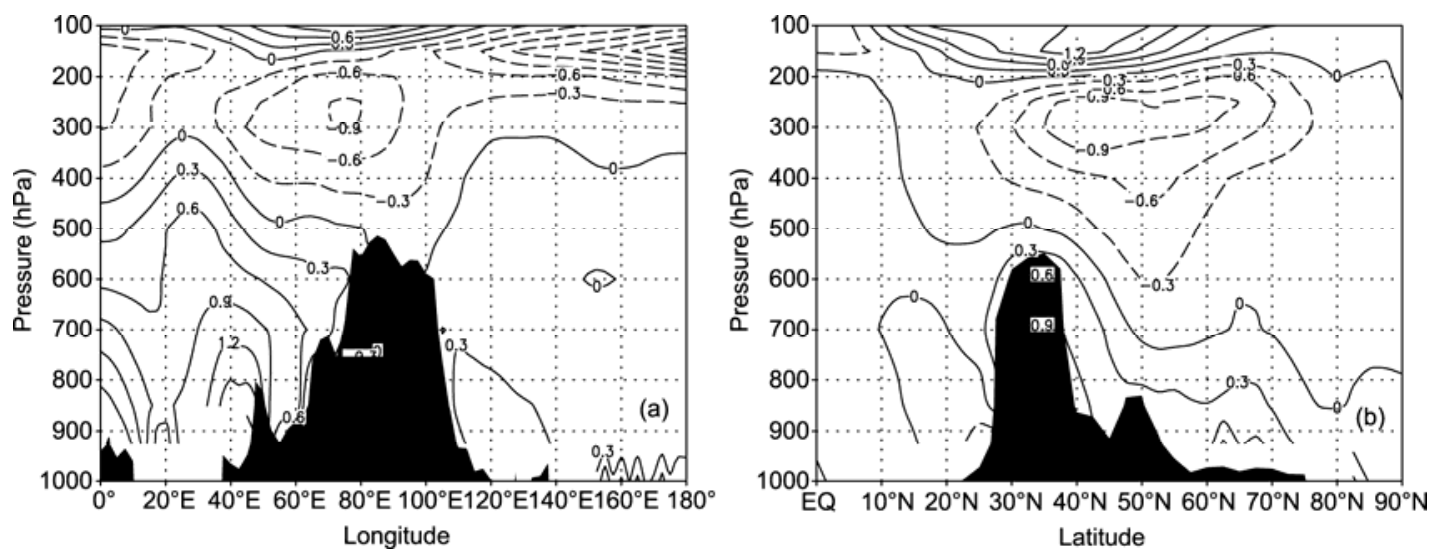

Figure 5 IPCC 9-model mean longitude-height cross-section of changes (K, relative to 1980-1999 average) in meridional thermal contrasts between the latitude belts over the TP and over the TIO for 2080-2099, i.e., the change in difference of the $20^{\circ}-40^{\circ} \mathrm{N}$ average minus that for the $10^{\circ} \mathrm{S}-10^{\circ} \mathrm{N}$ average. (b) Same as (a), but for the latitude-height cross-section of changes in zonal thermal contrasts between the longitude belts over the TP and over the NWP, i.e. change in difference between the $60^{\circ}-100^{\circ} \mathrm{E}$ average minus the $120^{\circ}-160^{\circ} \mathrm{E}$ average. Figure $5(\mathrm{a})$ was redrawn with IPCC 9 models based on Figure $3(\mathrm{c})$ the SunGRL paper.

greater than that over the TP at the same latitude. Careful analysis of the changes in moisture (not shown) reveals that it may also be related to the massive release of latent heating caused by the rise of sea surface temperature. This suggests that the increase in moisture and changes in cloud cover explain the enhanced upper-tropospheric warming in these areas. Thus, the thermal conditions in the upper-layer in the future climate can be affected by a range of factors. The involvement of feedback loops under a scenario of global climate change can also lead to changes in the difference within variables between the lower- and upper-layers.

Last, it should be noted that although many studies [16, 19,20] have investigated the differences between model predictions and observational data of enhanced upper-tropospheric warming, there remains considerable debate on this issue. A recent study [21] suggested that it may be related to deviations when calculating various radiosonde and satellite data.

\section{Discussions and conclusions}

We evaluated the influence of land-sea temperature rises on the SASM and EASM at a range of time scales. In South Asia, the changes in the summer monsoon are closely related to $\mathrm{TC}_{\text {upper }}$ at interannual, interdecadal, and longer time scales. The long-term weakening trend for the SASM is consistent with a decrease in $\mathrm{TC}_{\text {upper }}$ but in contrast to an increase in $\mathrm{TC}_{\text {lower }}$ over the TP-TIO. Conversely, in East Asia, the monsoon circulation is significantly correlated with $\mathrm{TC}_{\text {lower }}$ at the interannual time scale and with $\mathrm{TC}_{\text {upper }}$ at interdecadal and longer time scales. The long-term increasing trend for the EASM is in contrast to the weakening of $\mathrm{TC}_{\text {upper }}$, but consistent with the strengthening of $\mathrm{TC}_{\text {lower }}$ over the TP-NWP.

Further analyses of the thermal conditions in the mon- soon regions suggest that the TP-TIO and TP-NWP land-sea thermal contrasts will both strengthen in the lower-layer as the temperature increase in near-surface over the TP is greater than that in the lower-layer over the TIO and NWP. Conversely, in the upper-layer, the enhanced warming over the oceans is stronger than that over the TP, weakening the thermal contrasts over the TP-TIO and TP-NWP. Thus, the maximum temperature rise in the near-surface of the TP does not lead to the greatest increase in warming in the upper-layer of the region. The most intense warming is instead centered over the surrounding oceans due to the release of latent heat caused by an increase in moisture associated with global climate change.

Our analyses suggest that the land-sea thermal contrasts that drive monsoon formation may differ in the upper- and lower-troposphere in the future. As the warming center at near-surface does not necessarily correspond to that in the upper-layer, the changes in near-surface temperature may not be used as the basis for discussing future changes in thermal conditions in the upper-troposphere and explaining the changes in related circulation in many areas. The changes caused by feedback processes during climate change should also be carefully analyzed.

It is interesting that the correlations between the thermal contrasts and the SASM and EASM at multiple time scales may reflect the influence of external forcing. At interdecadal to longer time scales, the nearly linear increase of temperature likely reflects the influence of forcing caused by greenhouse gases. Under this scenario, the SASM and EASM relate somewhat differently to the upper- and lowerlayer thermal contrasts, likely due to differences in the properties of the SASM and EASM. The EASM consists of tropical and sub-tropical monsoons. The air-pressure gradient force caused by the land-sea thermal contrast exerts an important influence on it. Conversely, the SASM is primarily a tropical summer monsoon. As a direct dynamic response 
to the diabatic heating, the difference between upper- and lower-layer winds can be closely linked to the strength of the heat sources. Thus, the upper-layer thermal contrast is more important for the SASM. However, changes in the SASM and EASM at the interannual time scale are likely caused primarily by natural forcing. Both are significantly correlated to changes in $\mathrm{TC}_{\text {upper }}$, which are similar to those in the past 50 years. This likely reflects the natural variability in the climate and suggests that interactions between the two in the future will be similar to those in the current climate.

We observed some discrepancies in the simulation of the thermal conditions over the TP using the current climate models. Thus, arguments still remain with respect to the difference in enhanced warming over the tropical oceans between model output and observational data. Given this, the performance of the model needs to be improved with respect to simulating monsoon circulation, diabatic heating, and the variability at short time scales. Improvements in the climate models will continue to provide insights into the relationship between thermal conditions and changes in the Asian monsoon.

We thank two anonymous reviewers for helpful comments and suggestions. We acknowledge the international modeling groups for providing their data for analysis, the Program for Climate Model Diagnosis and Intercomparison (PCMDI) for collecting and archiving the model data, the JSC/CLIVAR Working Group on Coupled Modeling (WGCM) and their Coupled Model Intercomparison Project (CMIP), the Climate Simulation Panel for organizing the model data analysis activity, and the IPCC WG1 TSU for technical support. The IPCC Data Archive at Lawrence Livermore National Laboratory is supported by the Office of Science, US Department of Energy. And thanks also go to ECMWF for providing the ERA-4O data used in this study. This work was supported by the National Basic Research Program of China (2010CB428606) and the National Key Science and Technology Program of China (2007BAC29B01).

1 Jiang D B, Wang H J. Natural interdecadal weakening of East Asian summer monsoon in the late 20th century. Chinese Sci Bull, 2005, 50: 1923-1929

2 Meehl G A, Stocker T F, Collins W D, et al. Global Climate Projections. In: Climate Change 2007: The Physical Science Basis. In: Solomon S D, Qin D, Manning M, et al., eds. Contribution of Working Group I to the Fourth Assessment Report of the Intergovernmental Panel on Climate Change. Cambridge, United Kingdom and New
York: Cambridge University Press, 2007

3 Sun Y, Ding Y H. A projection of future changes in summer precipitation and monsoon in East Asia. Sci China Earth Sci, 2010, 53: 284-300

4 Sun Y, Ding Y H, Dai A. Changing links between South Asian summer monsoon circulation and tropospheric land-sea thermal contrasts under a warming scenario. Geophy Res Lett, 2010, 37: L02704

5 Fu C B, Fletcher J O. The relationship between Tibet-tropical ocean thermal contrast and interannual variability of Indian monsoon rainfall. J Clim Appl Meteoro, 1985, 24: 841-847

6 Meehl G A. Influence of the land surface in the Asian summer monsoon: External conditions versus internal feedbacks. J Clim, 1994, 7: 1033-1049

$7 \mathrm{Li} \mathrm{C} \mathrm{F}$, Yanai M. The onset and interannual variability of the Asian summer monsoon in relation to land-sea thermal contrast. J Clim, 1996, 9: 358-375

8 Ueda H, Iwai A, Kuwako K, et al. Impact of anthropogenic forcing on the Asian summer monsoon as simulated by eight GCMs. Geophys Res Lett, 2006, 33: L06703

9 Zhao P, Zhu Y, Zhang R H. An Asian-Pacific teleconnection in summer troposphric temperature and associated Asian climate variability. Clim Dyn, 2007, 29: 293-303

10 Holton J R. An Introduction to Dynamic Meteorology (4th ed). Burlington, MA: Elsevier Academic Press, 2004. 380-382

11 Chen $\mathrm{H} \mathrm{Q}, \mathrm{Wu} \mathrm{T}$, Dong W. Thermal contrast between the middle-latitude Asian continent and adjacent ocean and its connection to the East Asian summer precipitation. J Clim, 2008, 21: 4992-5007

12 Meehl G A, Covey C, Delworth T, et al. The WCRP CMIP3 Multimodel Dataset: A new era in climate change research. Bull Am Meteorol, 2007, 88: 1383-1394

13 Webster P J, Yang S. Monsoon and ENSO: Selectively interactive systems. Quart J Roy Meteor Soc, 1992, 118: 877-926

14 Wang B, Wu Z, Li J P, et al. How to measure the strength of the East Asian summer monsoon. J Clim, 2008, 21: 4449-4463

15 Sun Y, Solomon S, Dai A, et al. How often will it rain? J Clim, 2007, 20: 4801-4818

$16 \mathrm{Xu} \mathrm{K} \mathrm{M,} \mathrm{Emanuel} \mathrm{K} \mathrm{A.} \mathrm{Is} \mathrm{the} \mathrm{tropical} \mathrm{atmosphere} \mathrm{conditionally} \mathrm{un-}$ stable? Mon Weather Rev, 1989, 117: 1471-1479

17 Santer B D, Wigley T M, Mears C. Amplification of surface temperature trends and variability in the tropical atmosphere. Science, 2005, 309: 1551-1556

18 Dai A, Wigley T M, Bovilie B A, et al. Climates of the twentieth and twenty-first centuries simulated by the NCAR climate system model. J Clim, 2001, 14: 485-518

19 Santer B D, Thorne P W, Haimberger L, et al. Consistency of modelled and observed temperature trends in the tropical troposphere. Int J Climatol, 2008, 28: 1703-1722

20 Douglass D H, Christy J R, Pearsona B D, et al. A comparison of tropical temperature trends with model predictions. Int J Climatol, 2008, 28: 1693-1701

21 Titchner H A, Thorne P W, Mccarthy M P, et al. Critically reassessing tropospheric temperature trends from radiosondes using realistic validation experiments. J Clim, 2009, 22: 465-485

Open Access This article is distributed under the terms of the Creative Commons Attribution License which permits any use, distribution, and reproduction in any medium, provided the original author(s) and source are credited. 